УДК 811.134 .2

DOI 10.52575/2712-7451-2021-40-2-280-291

\title{
Местоимения vos и tú в испанском языке Монтевидео: восприятие носителей (на материале корпуса устной речи PRESEEA)
}

\author{
Стефанчиков И.В. \\ Московский государственный университет имени М. В. Ломоносова \\ Россия, 119991, г. Москва, Ленинские горы, д. 1 \\ E-mail: stefanchikov@protonmail.ch
}

\begin{abstract}
Аннотация. Представлены результаты исследования восприятия личных местоимений 2-го лица единственного числа vos и tú жителями г. Монтевидео (Уругвай). Проанализированы мнения информантов, высказанные ими в интервью из корпуса Proyecto para el estudio sociolingüístico del español de España y de América (PRESEEA). Подтверждено наличие в испанском языке Монтевидео двух параллельно функционирующих местоименных систем, а также сделано предположение о существовании третьей. Результаты могут быть использованы при дальнейшем изучении уругвайского национального варианта испанского языка (в частности, в исследованиях спонтанной речи).
\end{abstract}

Ключевые слова: испанский язык, Латинская Америка, Уругвай, личные местоимения, формы обращения, метаязыковая рефлексия.

Для цитирования: Стефанчиков И.В. 2021. Местоимения vos и tú в испанском языке Монтевидео: восприятие носителей (на материале корпуса устной речи PRESEEA). Вопросы журналистики, педагогики, языкознания, 40 (2): 280-291. DOI: 10.52575/2712-7451-2021-40-2-280-291

\section{Vos and tú in Montevidean Spanish: speakers' attitudes in the PRESEEA corpus}

\author{
Igor V. Stefanchikov \\ M.V. Lomonosov Moscow State University \\ GSP-1, Leninskie Gory, Moscow, 119991, Russia, \\ E-mail: stefanchikov@protonmail.ch
}

\begin{abstract}
This paper examines the attitudes of Uruguayan Spanish speakers towards the singular secondperson pronouns vos and tú. Our approach is based on the analysis of the 32 sociolinguistic interviews conducted in Montevideo, Uruguay from 2007 to 2011 as a part of the PRESEEA project. Traditionally, Montevidean Spanish was considered to have a tripartite system of pronoun address (vos, tú, usted), with tú as an intermediate option. However, recent studies show the increasing use of vos in detriment of tú. The results seem to confirm both opinions: while some speakers' repertoire only include two pronouns (informal vos and formal usted), the others still use all three options on a daily basis. Yet there are respondents having difficulty in describing the difference between vos and tú, which allows for an assumption that a third pronoun system, with no clear functional vos / tú distinction, might exist in Montevideo. We hope that our research will serve as a base for future experimental studies on pronouns in Uruguayan Spanish.
\end{abstract}

Keywords: Spanish, Latin America, Uruguay, personal pronouns, forms of address, linguistic attitudes.

For citation: Stefanchikov I.V. 2021. Vos and tú in Montevidean Spanish: speakers' attitudes in the PRESEEA corpus. Issues in Journalism, Education, Linguistics, 40 (2): 280-291 (in Russian). DOI: $10.52575 / 2712-7451-2021-40-2-280-291$ 


\section{Введение}

В современном испанском языке помимо местоимения формального обращения usted (ср. русское «Вы») существуют две основные опции для неформального обращения к собеседнику в единственном числе: тутео (tuteo - местоимение tú и/или соответствующие глагольные формы) и восео (voseo - местоимение vos и/или соответствующие глагольные формы). Эта вариативность носит прежде всего диатопический и диастратический характер: в некоторых испаноговорящих государствах бытует только один из вариантов (tú/vos), однако в большинстве стран встречаются оба, причём использование восео, вышедшего из употребления в «престижной» пиренейской разновидности испанской речи в XVIIXVIII вв., традиционно стигматизируется языковой нормой [Lipski, 1996, p. 159].

Регионы сосуществования tú и vos, к которым относится и Уругвай, характеризуются наличием «смешанной» системы с двумя местоимениями неформального обращения (Sistema pronominal III), которая, по мнению М. Б. Фонтанеллы де Вайнберг, делится на два подвида [Fontanella de Weinberg, 1999, p. 1404-1405].

В первом, наиболее распространённом (подвид ІІІа, табл. 1), vos и tú находятся в отношениях свободного варьирования («иna alternancia bastante generalizada de formas, sin una delimitación funcional» [ibid.]), а разграничение между ними носит, скореe, социостилистический характер: литературная норма отдаёт предпочтение $t u ́$.

Таблица 1

Table 1

Местоименная система IIIa [ibid., p. 1404].

Pronoun system IIIIa

\begin{tabular}{|c|c|c|}
\hline Ámbitos & SINGULAR & PLURAL \\
\hline Confianza & vos $\sim$ tú $^{*}$ ustedes \\
\hline Formalidad & usted & \\
\hline
\end{tabular}

Во втором подвиде (IIIb, табл. 2), ареал распространения которого Фонтанелла де Вайнберг ограничивает Уругваем, местоимения 2-го л. ед. ч. образуют градацию: vos tú - usted (от наибольшей степени близости между собеседниками к наибольшей дистанции). Внутри сферы неформального обращения vos употребляется в контекстах «близости» (intimidad), в то время как tú - в контекстах «солидарности» (solidaridad), т. е. коммуникативного равенства, при котором, однако, дистанция не сведена к минимуму:

Таблица 2

Table 2

Местоименная система IIIb [ibid.]

Pronoun system IIIb

\begin{tabular}{|c|c|c|}
\hline Ámbitos & SINGULAR & PLURAL \\
\hline Intimidad & vos & \multirow{2}{*}{ ustedes } \\
\hline Confianza & tú \\
\hline Formalidad & usted & \\
\hline
\end{tabular}

Картина, однако, усложняется тем обстоятельством, что в испанском языке местоименные формы восео могут сочетаться с глагольными формами тутео - и наобо- 
рот. В связи с этим в испанистике принято говорить о трех типах восео [RAE-ASALE, 2009, p. 206]:

1. Полное восео (voseo completo, также V-V): vos tenés / vos tenéi(s) / vos tenís.

2. Глагольное восео (voseo flexivo, T-V): tú tenés / tú tenís.

3. Местоименное восео (voseo pronominal, V-T): vos tienes.

В Уругвае встречаются все 4 варианта соотношения между восео и тутео: vos cantás (V-V, наиболее употребительный вариант, преобладающий на большей части территории Уругвая [ibid., 2009, p. 1265]), tú cantás (T-V, вариант, распространённый в Монтевидео наряду с основным), tú cantas (T-T, вариант, преобладающий в некоторых регионах страны и используемый в образовательной сфере как «престижный»), vos cantas (V-T, наименее распространённый вариант, встречающийся на границе с Бразилией [Carvalho, 2010]).

Смешанная форма обращения T-V (tú cantás) была впервые упомянута в филологических работах как характерная для Монтевидео в 1960-х [Ricci, Malán de Ricci, 1962/63] и в дальнейшем неоднократно отмечалась в качестве черты, выделяющей речь Монтевидео на фоне других разновидностей испанского языка в регионе Рио-де-ла-Плата [Rona, 1967; Elizaincin, 1992; Bertolotti, Coll, 2006].

В рамках данного исследования мы сосредоточимся на восприятии жителями Монтевидео соотношения между местоимениями 2-го л. ед. ч. vos и tú. Поскольку глагольные формы тутео, а вместе с ними сочетания типа Т-Т являются малоупотребительными в столице Уругвая, речь фактически пойдёт о разнице между формами обращения V-V и T-V.

\section{Объекты и методы исследования}

Материалом исследования стал корпус устной речи Монтевидео, являющийся составной частью проекта Proyecto para el Estudio Sociolingüístico del Español de España y de América [PRESEEA, 2014]. Этот проект посвящён изучению речи городов Испании и Латинской Америки. Каждый город представлен в PRESEEA 54 интервью, состав которых сбалансирован по полу информантов, их возрасту $(18-34,35-54,55+)$ и образованию (начальное, среднее, высшее).

На сайте PRESEEA (preseea.linguas.net) доступны транскрипции 54 интервью с носителями, взятых в Монтевидео с 2007 по 2011 год, и соответствующие аудиофайлы. Интервью длятся от 35 до 75 минут и содержат в среднем около 7 тысяч слов. Все они проходят по схожему сценарию: интервьюер уточняет, какое местоимение ему следует использовать при обращении к информанту, затем следуют тематические блоки: обсуждение погоды, жилища, семьи и друзей, привычек, забавных случаев из жизни и т. д.

В 32 из 54 интервью (20 носителей-женщин и 12 мужчин; возрастной диапазон - от 19 до 87 лет) содержатся высказанные информантами суждения относительно использования ими в речи тех или иных местоимений, что представляет собой уникальную особенность корпуса. Подобные сведения особенно ценны, учитывая, что испанский (с некоторыми оговорками) относится к языкам с нулевым субъектом, то есть к тем, в которых эксплицитное выражение субъекта избыточно, а потому факультативно.

В рамках настоящего исследования мы сконцентрировались на анализе мнений носителей о контекстах и факторах, влияющих на использование местоимений vos и tú. Отдавая себе отчёт в том, что выводы о языковой ситуации не могут основываться на метаязыковой рефлексии носителей, мы, однако, рассматривали данную ступень анализа как вспомогательную для дальнейших этапов исследования форм обращения в уругвайском варианте испанского языка.

Информация о примерах указывается в следующем формате: [номер интервью, пол информанта, его возраст]. Сохранены исходные условные обозначения и разметка текста: $E$ (entrevistador) - интервьюер; I (informante) - информант; / - краткая пауза; // - пауза; $\langle$ cita $\rangle\langle/$ cita $\rangle$ - цитата; <alargamiento/> - удлинённое произнесение звука; $<$ énfasis $></ e ́ n f a s i s>-$ интонационная эмфаза; <entre_risas ></entre_risas > - фрагмент, про- 
изнесённый сквозь смех; <risas = "E"/> - смех, с указанием смеющегося; <vacilación/> колебание, сомнение, выраженное интонационно. Кроме того, для удобства автором статьи были выделены заглавными буквами случаи использования местоимений в контекстах метаязыковой рефлексии, а сочетанием символов $<\ldots>-$ пропуски в тексте.

\section{Результаты и их обсуждение}

\section{Трёхчастная система: vos - tú - usted}

Основными факторами, определяющими выбор местоимения, являются, по мнению респондентов, возраст собеседника, отношения между говорящими и ситуация разговора.

Использование usted рассматривается носителями как эксплицитное проявление уважения, особенно в общении с людьми старшего возраста (принятие «поколенческих ролей»). Респонденты в целом сходятся во мнении, что это местоимение «состаривает» того, к кому оно обращено: «me hace sentir más vieja» [Е47 - Ж - 39]. Многие отмечают, что usted в речи молодых носителей всё чаще уступает место неформальным аналогам, что вступает в конфликт с речевым этикетом старших поколений, выросших в обществе, где оно использовалось гораздо чаще (к примеру, в общении с родителями): «ihabía chiquilines que ni a los padres tuteaban!» [E18 - Ж - 86].

В целом, мнения значительной части информантов сообразуются с наблюдениями, указывающими на существование трёхчастной системы vos - tú - usted (IIIb), описанной Фонтанеллой де Вайнберг. Эта категория носителей использует местоимение tú, а некоторые предпочитают его другим способам неформального обращения:

E.: ¿cómo te gusta que te traten a ti?

I.: de $T U ́$ [E1 - Ж - 36]

I.: el vos no mucho / pero el TÚ <vacilación/> es es habitual en mí [E7 - Ж - 56] Ж-66]

I.: el VOS<alargamiento/> no / no me ha entrado <vacilación/> más más el tuteo [E14 -

$T u ́$ занимает промежуточное положение: оно является местоимением неформального обращения на фоне usted и при этом рассматривается носителями как способ сохранить некоторую дистанцию с собеседником (чего не позволяет vos):

I: de TÚ así como un intermedio entre VOS y USTED [E3 - Ж - 22]

I: quizás con los que tengo más familiaridad / o o o / a veces también de manera enfática el VOS <...> el TÚ me parece eh un tratamiento como más delicado que el VOS / el VOS me parece más inmediato / más fuerte [E12 - Ж - 69]

В трёхчастной системе местоимению tú по сравнению с vos отведены более формальные контексты: оно используется в ситуациях «преподаватель-студент», «врачпациент», «покупатель-продавец», «коллеги». Говорящий в таких случаях делает выбор между подчёркнуто вежливым usted и tú, не создающим чрезмерной дистанции. В следующем примере носитель - учительница в средней школе, ученики которой, по её словам, обычно обращаются к ней на tú:

E.: ¿tú tenés alumnos? < ... ¿cómo te tratan?

I.: de $T U^{\prime}<\ldots>$ de VOS no

E.: ¿ni uno te trata de VOS?

I.: no<alargamiento/>

$<\ldots>$

E.: o sea que van entre USTED y TÚ / pero nunca VOS

I.: no $[\mathrm{E} 1-Ж-36]$ 
$T u ́$ также может использоваться при обращении к незнакомому человеку среднего или младшего возраста. Отсутствие личного знакомства «исключает» опцию vos, но и местоимение usted воспринимается как неуместное - как в двух следующих примерах. В первом речь идёт о контексте неформального общения (вечеринке), во втором - об обращении к незнакомому, но молодому человеку на улице. В обоих случаях носители делают выбор в пользу tú:

I.: en una reunión social lo voy a tutear

$<\ldots>$

E.: tutear ¿significa <énfasis $>T U ́</$ énfasis $>$ ?

I.: $T U^{\prime}$

E.: $n o / V O S$

I.: $n o[\mathrm{E} 1-Ж-36]$

E.: bien ¿y si vas por la calle / y tenés que preguntarle algo a alguna persona que no conocés / cómo te dirigís a ella?

I.: < ..> si es una persona joven / le digo de TÚ / ahi si / y<alargamiento/> si es una persona que la veo mayor <vacilación/> / que yo / eh ahí la trato de USTED [E17 - Ж - 56]

Местоимение vos в трёхчастной системе является наиболее неформальным выбором, характерным для общения в семейном или дружеском кругу, когда дистанция между собеседниками минимальна:

I: por ejemplo te atiende una empleada en una tienda o no sé en cualquier comercio o en un despacho de un médico lo que sea / TÚ < ... puedo decirle TÚ pero de ahí no pasa la cosa ni para arriba ni para abajo / VOS no / no no / no / lo tengo muy incorporado el VOS a nivel familiar si $<$ cita $>$ che vos $</$ cita $>[\mathrm{E} 13-\mathrm{M}-61]$

К кругу лиц, к которым уместно обращение на vos, носители относят родственников, друзей, соседей:

I: el VOS / con mis padres el VOS [E6 - M - 29]

E.: por ejemplo ¿cómo tratás a / a tus amigos?

I.: de $\operatorname{VOS}[\mathrm{E} 3-Ж-22]$

По мнению носителя № 6, местоимение vos предназначено для общения с людьми, к которым говорящий питает наибольшую симпатию (в противоположность холодноуважительному usted): speto que?

E.: ¿y a vos te parece que el USTED < ... $>$ es una muestra de $<$ alargamiento/> mayor re-

I.: < ...> no sé me parece que / como de más respeto el VOS < ..> más <vacilación/> más cercano así $[\mathrm{E} 6-\mathrm{M}-29]$

При этом выбор местоимения (tú / vos) может зависеть как от отношений с собеседником (более или менее близких), так и от особенностей коммуникативной ситуации (регистра общения):

I.: y si si le estoy hablando a una persona este con la que no tengo mucho vínculo quizá lo trate de TÚ // pero si tengo más relació<alargamiento $>$ n hablo de VOS $<\ldots>$ si es algo más formal / hablo de TÚ y si es algo una conversación más coloquial más distendida hablo de VOS [E11 - Ж - 34] 
Местоимение vos сокращает психологическую дистанцию между говорящими до минимальной. Именно поэтому оно, по мнению носителя № 15, не подходит, к примеру, для обращения к вышестоящим на работе:

I.: pero hay gente que por ejemplo no lo puedo tratar de de VOS / como por ejemplo eh mis jerarcas / en el trabajo [E15 - Ж - 56]

Информант №1 полагает, что в таких контекстах предпочтительнее использование usted или tú (выбору последнего благоприятствует давнее знакомство; тогда данное местоимение не является знаком неуважения, а лишь проявлением доверия):

I.: el trato con ellos me merece una cierta confianza / donde ellos ven que el trato de TÚ I no le estoy faltando el respeto a la persona / sino que es de tantos años juntos [E1 - Ж - 36]

Респондент № 9, диетолог, сообщает, что при обращении к пожилым клиентам использует usted, а в общении со сверстниками и более молодыми людьми корректным с точки зрения речевого этикета выбором может быть и местоимение tú:

I.: algunos de ellos se dirigen de USTED / y bueno / se ve que quieren marcar distancia y es general mantener / cierta distancia / aunque lo podés tratar de TU / y ser respetuoso igual / no viene por ahi $[\mathrm{E} 9-Ж-44]$

Стратегия переосмысления tú как вежливой формы в условиях «отступления» чересчур формального usted, была рассмотрена в [Моyna, 2017].

«Промежуточная» роль tú может проявляться и в семейном кругу - например, при обращении к бабушкам и дедушкам. Tú в таких случаях позволяет, с одной стороны, оставаться в рамках неформального общения, с другой - отдать дань возрасту родственника и его авторитету.

E.: ¿y a tus abuelos como los tratás?

I.: ide $T U ́$ ! / de TÚ / los trataba / de $T U ́$

E.: TÚ / siempre TÚ / ¿no VOS?

I.: no

E.: $T U^{\prime}$

I.: sí porque me enseñaron asi $[\mathrm{E} 1$ - Ж - 36]

Таким образом, если исходить из данных интервью, местоимение tú сохраняется в Монтевидео в речи по крайней мере части носителей: 45 респондентов в ходе интервью использовали vos, 23 - tú (из подсчёта исключены случаи употребления местоимений в ходе обсуждения языковых форм), причём многие использовали оба местоимения, а носители № 9, 12, 55, 56 за время интервью ни разу не произнесли vos, сделав выбор в пользу tú.

Некоторые опрошенные - респондент № 7 или № 13 и № 14 (супружеская пара) отметили, что предпочитают использовать не только местоимение tú, но и глагольные формы тутео (sabes, haces, necesitas и т. п.):

E.: pero vos cómo decís / por ejemplo / <cita> ¿TÚ sabés o TÚ sabes? </cita>

I.: no / <cita $>$ TÚ sabes profesor / o <alargamiento/ $><$ cita $>[\mathrm{E} 7-$ Ж -56$]$

I.: no no <cita> TÚ haces </cita> por ejemplo es muy común en mí decirlo / TÚ te ocurre tal cosa o TÚ necesitas algún documento mio [E13 - M - 61]

I.: $<$ cita $>T U ́$ / TÚ tienes / dime $</$ cita $>/ /$ no todo pero hay hay $<$ cita $>$ decime $</$ cita $>$ de repente / de repente lo digo pero / me suena mejor <cita> dime / JC / VOS este tal cosa $</$ cita $>[\mathrm{E} 14-$ - -66$]$ 
Из приведённой цитаты следует, что носитель № 14 в повседневной речи использует как глагольные формы восео (tenés, decime), так и тутео (tienes, dime), воспринимая последние как более корректные (более того, в приведённом ею примере форма тутео в повелительном наклонении сочетается с обращением vos). Интервьюируемая в целом негативно оценивает восео с эстетической точки зрения:

I.: a mi me choca / o al escribirlo en computadora a mi hermano que vive en Caracas / por ejemplo / este / lo hago / porque él escribe asi / entonces <entre_risas> me parece que yo / un poco / caigo un poco en el / en el rococó siempre </entre_risas $>$ [E- $14-Ж-66]$

В то же время в ходе интервью носители № 13 и 14 использовали оба местоимения.

\section{Двухчастная система: vos - usted}

Помимо трёхчастной системы, считающейся «визитной карточкой» Монтевидео, на основании ответов респондентов мы можем сделать предположение о существовании двухчастной системы vos - usted (Sistema pronominal IV, табл. 3), которая обычно описывается как характерная для Аргентины и ряда регионов Центральной Америки [Fontanella de Weinberg, 1999, p. 1406].

Таблица 3

Table 3

Местоименная система IV [ibid.]

Pronoun IV system

\begin{tabular}{|l|c|c|}
\hline \multicolumn{1}{|c|}{ Ámbitos } & SINGULAR & PLURAL \\
\hline Confianza & vos & ustedes \\
\cline { 1 - 2 } Formalidad & usted & \\
\hline
\end{tabular}

Многие информанты утверждают, что не употребляют местоимение $t u ́$ или делают это крайне редко:

I.: yo nunca uso TÚ / nunca <... me parece que son más / bastante parecidos $<\ldots>$ pero<alargamiento/> yo no no lo uso / uso más que nada el VOS < ... < <ita $>$ TÚ sabes $</$ cita> por ejemplo / no / no / no me acuerdo de haberlo usado [E6 - M - 29]

E.: con VOS / y nunca o casi nunca <énfasis $>T U ́$ < <énfasis $>$ dices TÚ a alguien

I.: no / rara vez / pero no $[\mathrm{E} 4-\mathrm{M}-54]$

Другие, кроме того, отмечают, что не знакомы практически ни с кем, кто бы использовал данное местоимение:

E.: ¿y conocés gente que <...> te hable de TÚ? / acá en Montevideo

I.: no $[\mathrm{E} 40-Ж-31]$

I.: el TÚ / no <... $>$ nunca

E.: ahi está / y conocés gente que lo use / algún amigo o gente de afuera

I.: conocer sí / no son muchos pero algún conocido tengo sí [E41- M - 41]

Таким образом, в арсенале этих носителей единственным местоимением неформального обращения (в котором сливаются контексты «близости» и «солидарности») является vos, противопоставленное «вежливому» usted. 
I.: y / depende si es una persona muy mayor o es una persona joven / si es más mayor de repente lo trato de USTED / y si es menor de VOS [E16 - Ж - 19]

Любопытно и то, что в 53 случаях из 54 интервьюеры хотя бы один раз за время беседы употребили местоимение vos и лишь в 18 - использовали также и tú. С одной стороны, подобные цифры демонстрируют причудливое сосуществование в испанском языке Монтевидео двух местоимений, переключение между которыми может неоднократно происходить в рамках одного диалога, порой незаметно для носителя. С другой - позволяют обратить внимание на возможную тенденцию вытеснения tú.

Исследование Дж. Уэйерса показало, что в репертуаре носителей моложе 40 лет (в отличие от представителей более возрастных групп) местоимение $t u ́$ фактически отсутствует, полностью уступив место vos. Автор делает прогноз: tú исчезнет из речи жителей Монтевидео через одно-два поколения [Weyers, 2009, 837-838]. Описанная тенденция находит подтверждение в работах, анализирующих использование местоименных и глагольных форм в образовательном контексте, где позиции тутео традиционно были максимально прочными [Weyers, Canale, 2013], а также в рекламных текстах [Costa, da Conceição, 2011; Uber, 2021].

Данные рассматриваемого корпуса, однако, несколько противоречат наблюдениям Уэйерса. 11 из 25 респондентов в возрастной группе до 40 лет хотя бы раз использовали формы местоимения tú в общении с интервьюером. Кроме того, некоторые из них (№ 1, 36 лет; № 11, 34 года; № 52, 29 лет) эксплицитно сообщили, что оно входит в их репертуар:

E.: ¿estás acostumbrada a tratar a los demás de VOS?

I.: no / de TÚ [E52 - Ж -29]

Носитель № 1 (учительница в средней школе), по собственному признанию, приучила обращаться к собеседникам на tú и своего 4-летнего сына:

I.: tú sabes que yo a mi hijo lo lo eduqué asi $/$ y $<\ldots>$ mi hermana $<\ldots>$ le pide hasta el día de hoy a Agustín / que <cita > yo / soy VOS no / me trates de TÚ </cita > / porque Agustín trata de TÚ / tiene cuatro años <... y no le sale <énfasis $>$ VOS < lénfasis $>[\mathrm{E} 1-Ж-36]$

Другие примеры употребления tú в возрастной группе до 40 лет мы находим в работе М. Дуарте Фаваро, основанной на записях спонтанной речи. Так, при первой встрече с незнакомым человеком (самим исследователем) работница магазина (оценочный возраст - 20 лет), сделала выбор в пользу «вежливого» местоимения usted (;Buenas tardes! ¿Es nuevo en el barrio usted?), а с третьего визита и далее использовала T-V (;Buenas! ¿Todavía andás por acá tú??) [Duarte Favaro, p. 14].

Ещё один пример, который приводится в статье (девушка, отвергающая ухаживания), свидетельствует о том, что местоимение $t u ́$ может ситуативно применяться людьми, обычно обращающимися друг к другу на vos, для увеличения психологической дистанции:

Hombre: Ahora vos decime... ¿querés que nos veamos el viernes entonces?

Mujer: Ay, no sé, ya sabés que estoy saliendo con alguien.

Hombre: ¡Dale, hace tiempo que me gustás!

Mujer: ;Sos pesado tú! ¿Eh? [ibid., p. 16]

М. И. Мойна также отмечает, что носитель в пределах одного коммуникативного акта может переходить от tú, смягчающего просьбу ( ¿Tú no me devolverías la plata?), к vos, добавляющему категоричности требованию: ;Vos devolveme la plata ya! [Moyna, 2015, p. 4]. Иными словами, выбор личного местоимения и/или глагольной формы может быть чувствителен к прагматическим изменениям в ходе речевого акта. 
Отдельно следует сказать об использовании tú в типизирующих контекстах, когда местоимение отсылает не к личности собеседника, но к обобщенному «ты» (т. н. tú genérico, встречающееся, например, в гипотетических ситуациях):

I: por ejemplo / caminando por Dieciocho túu ves // policíalargamiento/>as / en las esquinas [E16 - Ж - 19]

«Гибрид» T-V сохраняет свою роль и как маркер монтевидеанской, уругвайской идентичности на фоне соседнего Буэнос-Айреса, где подобное сочетание не засвидетельствовано. Сложная и противоречивая история взаимоотношений двух столиц накладывает свой отпечаток на языковое сознание. Ряд лингвистов связывает в целом положительное отношение к местоимению tú и смешанной форме T-V в Монтевидео с ощущением языковой «самости» [Bertolotti, Coll, 2006; Weyers, 2013; Moyna, Loureiro-Rodríguez, 2017].

Эти и другие наблюдения корректируют выводы Уэйерса и позволяют предполагать, что tú, вытесняемое своим аналогом vos, всё же не пропадает из речи молодых жителей Монтевидео полностью.

\section{Неразличение vos и tú. Региональные особенности}

Интервьюируемые не всегда чётко очерчивают границы употребления двух местоимений, лишь упоминая их оба как возможные, но не объясняя факторов, влияющих на выбор того или иного варианта, как, например, носитель № 54:

E.: ¿voseás también? ¿decís VOS a la gente?

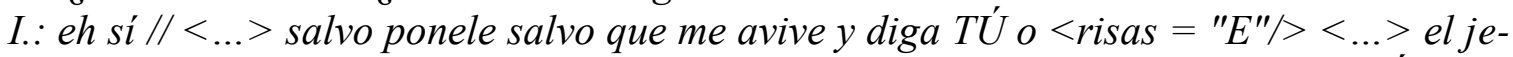
fe no pero ponele / después al contador y eso sí / o sea / no no también le digo VOS / TÚ / embromo un poco / con ellos <...> es todo muy // es medio familiar ahí [E54 - M - 24]

При этом важно, что многие носители - как (по собственному признанию) использующие tú, так и нет - слабо различают два местоимения, порой не обращая внимания на то, какое именно было использовано собеседником. Это может объясняться общностью глагольных форм двух способов обращения (V-V и $\mathrm{T}-\mathrm{V})$, учитывая характер испанского как языка с нулевым субъектом - глагольные формы частотнее, а потому заметнее:

I: pero en realidad mi oído no no percibe mucho / sí si me dicen tienes en lugar de tenés / pero no si me dicen TÚ tenés o VOS tenés para mí es medio / indiferente $<\ldots>$ sí nos pasa desapercibido [E2 - Ж - 36]

\section{I.: USTED / no < .. > ahora / nunca he prestado atención si VOS o TÚ [E1 - Ж - 36]}

Респонденты зачастую не отдают себе отчёта и в том, какое местоимение они сами использовали в той или иной ситуации: Ж -44$]$

I.: en lo cotidiano / empleo el VOS / o el TÚ < ... este / sin darme cuenta a veces [E9-

Два местоимения тесно связаны в испанском языковом сознании, что проявляется и на уровне терминологии: глаголом tutear и существительным tuteo может обозначаться как обращение на vos, так и на tú. В определении лексемы tutear в словаре Испанской королевской академии не сказано о выборе конкретного местоимения: 1. tr. Dirigirse a alguien empleando el pronombre de segunda persona para el trato de confianza o familiaridad. U. t. c. prnl. 
То же касается выражения tratar(se) de tú. Носитель № 8, который на протяжении интервью обращается к интервьюеру исключительно на $v o s$, в ответ на вопрос: « $i y$ vos como solés tratar a las personas? ¿solés tratarlas de vos, de usted?», отвечает «de tú siempre», причём остаётся непонятным, что именно он имел в виду. Всё это порождает необходимость дополнительного уточнения, как в следующем примере:

E.: y a vos en general te gusta que te traten de TÚ

I.: sí

E.: o sea

I.: de VOS

E.: de VOS de VOS [E3 - Ж - 22]

Отдельно следует сказать о региональных особенностях в употреблении местоимений, которые упоминает часть носителей (4 из 54 интервьюируемых родились вне Монтевидео). Восео имеет широкое распространение на территории Уругвая, однако существуют регионы, отклоняющиеся от общего правила. Зоной преобладания тутео (местоименного и глагольного, т. е. Т-Т) считаются департаменты Роча и Мальдонадо на востоке страны [Di Tullio, Malcuori, 2012, p. 81] и некоторые районы департамента Канелонес [RAE-ASALE, p. 1253].

Информант № 10 относит свой родной регион (департамент Колония) к зоне аргентинского влияния и объясняет распространенность восео географической близостью к соседу и воздействием его культурной продукции, а ареалом тутео справедливо считает восточную часть Уругвая:

I.: estee / entonces en general<alargamiento/> el TÚ o el VOS / más que nada el VOS porque insisto / soy del interior pero especificamente de Nueva Helvecia / Colonia / zona de influencia argentina / entonces / televisión / radio etcétera etcétera trae el voseo es algo mucho más establecido que el TÚ / de pronto que puede ser más del lado del este ¿no? [E10 - Ж - 48]

Респондент № 34 также демонстрирует знание уругвайской языковой реальности, называя Рочу и Мальдонадо регионами бытования тутео. В Монтевидео, по его мнению, чаще употребляется восео:

I.: no / sería tuteo si estuviéramos en Maldona $<$ alargamiento/ $>$ do o en Rocha / pero acá<alargamiento/> es VOS [E34 - M - 62]

\section{Заключение}

Рассмотрение эксплицитно выраженных мнений носителей, содержащихся в 32 интервью корпуса PRESEEA, позволило нам увидеть сложную картину употребления форм обращения в испанском языке Монтевидео.

По свидетельству части информантов, местоимение $t u ́$ в их речи занимает промежуточное положение между vos и usted. Данный результат в каком-то смысле соответствует исследовательским ожиданиям, поскольку трёхчастная местоименная система IIIb неоднократно фигурировала в описаниях испанского языка Уругвая. Более того, в ходе анализа были обнаружены носители, в репертуар которых входят глагольные формы тутео.

Вместе с тем некоторые респонденты заявили, что в их речи vos - единственное местоимение неформального обращения. Такая местоименная система (vos - usted; Sistema pronominal IV), характерная для риоплатского лингвистического региона, по всей видимости, будет укреплять свои позиции в уругвайской столице: ряд исследователей обращает внимание на тенденцию к вытеснению $t u ́$.

Кроме того, часть носителей, использующих в речи vos и tú, столкнулась с проблемами при попытке описать разницу между двумя местоимениями, что даёт основания 
предполагать возможность существования в Уругвае системы IIIa, в которой между ними отсутствует чёткое функциональное разделение. Подобное предположение высказывалось также в исследовании, проведённом на материале 12 интервью из того же корпуса [Shively, 2016, p. 248], однако оно нуждается в проверке.

Наконец, анализ выявил и другие формы (такие, как che и vo / bo), использующиеся в уругвайском национальном варианте испанского языка для обращения к собеседнику. Рассмотрение особенностей их употребления, однако, не входило в задачи исследования.

Осознавая принципиальные ограничения настоящего исследования (анализ метаязыкового восприятия говорящих не может подменять собой анализ языковой реальности; следует также учитывать фактор временно́й амортизации материала), мы, тем не менее, убеждены, что его результаты окажутся полезными в дальнейшем изучении особенностей использования местоименных и глагольных форм в испанском языке Уругвая. Ответы на вопросы, поставленные здесь, могут быть получены с помощью экспериментальных исследований спонтанной речи.

\section{References}

1. Bertolotti V., Coll M. 2006. Apuntes sobre el español en el Uruguay: historia y rasgos caracterizadores [Notes on Spanish in Uruguay: history and characterizing features]. Ámbitos, 16: 31-40. (in Spanish)

2. Carvalho A.M. 2010. ¿Eres de la frontera o sos de la frontera? Variation and alternation of second-person verbal forms in Uruguayan border Spanish [Eres de la frontera o sos de la frontera? Variation and alternation of second-person verbal forms in Uruguayan border Spanish]. Southwest Journal of Linguistics, 29: 1-23. (in English)

3. Costa B., da Conceição C. 2011. La variación de las fórmulas de tratamiento de segunda persona del singular en publicidades de Montevideo [The variation of the formulas for treating the second person singular in advertisements in Montevideo]. Diadorim, 8: 375-395. (in Spanish)

4. Di Tullio Á., Malcuori M. 2012. Gramática del español para maestros y profesores del Uruguay. Montevideo [Spanish grammar for teachers from Uruguay]. ANEP, 443 p. (in Spanish)

5. Duarte Favaro M. 2011. ¿Y tú de donde sos?: Estudio cualitativo sobre el uso específico del tuteo en el habla montevideana [Where are you from ?: Qualitative study on the specific use of tuteo in Montevideo speech]. Available at: http://diva-portal.org/smash/record.jsf?pid=diva2\%3A427633 (accessed: 01.04.2021) (in Spanish)

6. Elizaincin A. 1992. El español actual en el Uruguay [Current Spanish in Uruguay]. In: Hernández C. (coord.) Historia y presente del español de América [History and present of the Spanish of America]. Valladolid, Publ. Junta de Castilla y León: 759-774. (in Spanish)

7. Fontanella de Weinberg M.B. 1999. Sistemas pronominales de tratamiento usados en el mundo hispánico [Pronominal treatment systems used in the Hispanic world]. In: Bosque I., Demonte V. (dirs.), Gramática descriptiva de la lengua española [Descriptive grammar of the Spanish language]. Vol. 1. Madrid, Publ. Espasa Calpe: 1404-1405. (in Spanish)

8. Lipski J. 1996. El español de América [The Spanish of America]. Madrid, Publ. Cátedra, 446 p. (in Spanish)

9. Moyna M.I. 2015. Voseo / Tuteo Variation in Uruguayan Popular Songs (1960-2010) [Voseo / Tuteo Variation in Uruguayan Popular Songs (1960-2010)]. Romanische Forschungen, 127 (1): 3-28. (in German)

10. Moyna M.I. 2017. Strategies of polite address in Uruguayan Spanish: Is tú the new usted? INAR 4 Helsinki, June 8-9, 2017. (in English)

11. Moyna M.I., Loureiro-Rodríguez V. 2017. La técnica de máscaras emparejadas para evaluar actitudes hacia formas de tratamiento en el español de Montevideo [The paired mask technique to assess attitudes towards forms of treatment in the Spanish of Montevideo]. RILI, 15 (2): 47-82. (in Spanish)

12. PRESEEA. 2014. Corpus del Proyecto para el estudio sociolingüístico del español de España y de América [Corpus of the Project for the Sociolinguistic Study of Spanish in Spain and America]. Universidad de Alcalá. Available at: http://preseea.linguas.net (дата обращения: 01.04.2021). (in Spanish) 
13. RAE-ASALE. 2009. Nueva gramática de la lengua española [New grammar of the Spanish language]. Madrid, Espasa, 4032 p. (in Spanish)

14. Ricci J., Malán de Ricci I. 1962/63. Anotaciones sobre el uso de los pronombres tú y vos en el español del Uruguay [Notes on the use of the pronouns tú and vos in Uruguayan Spanish]. Anales del Instituto de Profesores Artigas, 7-8: 163-166. (in Spanish)

15. Rona J.P. 1967. Geografía y morfología del «voseo» [Geography and morphology of «voseo»]. Pôrto Alegre, Publ. Pontifícia Universidade Católica do Rio Grande do Sul, 116 p. (in Portuguese)

16. Shively A. 2016. Voseo, tuteo y ustedeo en el español uruguayo: uso, variación pragmática y cambios generacionales [Voseo, tuteo y ustedeo in Uruguayan Spanish: use, pragmatic variation and generational changes]. IULC Working Papers, 15 (1): 231-256. (in Spanish)

17. Uber D. 2021. "Feel really Uruguayan". In: (Ed.) Díaz-Campos M., Sessarego S. Aspects of Latin American Spanish Dialectology. John Benjamins Pub. Co.: 29-46. (in English)

18. Weyers J. 2009. The Impending Demise of tú in Montevideo, Uruguay. Hispania, 92.4: 829839. (in English)

19. Weyers J. 2013. Linguistic attitudes toward the tuteo and voseo in Montevideo, Uruguay. Spanish in Context, 10 (2): 175-198. (in English)

20. Weyers J., Canale G. 2013. Tuteo and voseo in the classroom: Linguistic attitudes among Montevidean educators. Spanish in Context 10 (3): 371-389. (in English)

\section{ИНФОРМАЦИЯ ОБ АВТОРЕ}

Стефанчиков Игорь Вячеславович, аспирант кафедры иберо-романского языкознания филологического факультета МГУ имени М. В. Ломоносова, г. Москва, Россия

\section{INFORMATION ABOUT THE AUTHOR}

Igor V. Stefanchikov, Post-Graduate Student, Department of Ibero-Romance Linguistics, Faculty of Philology, Lomonosov Moscow State University, Moscow, Russia 